\title{
Effects of Job Evaluation on Decisions Involving Pay Equity
}

\author{
Isaac Chaneta ${ }^{1}$ \\ ${ }^{1}$ Faculty of Commerce, Arts \& Social Studies, University of Zimbabwe, Zimbabwe \\ Correspondence: Isaac Chaneta, Faculty of Commerce, Arts \& Social Studies, University of Zimbabwe, \\ Zimbabwe. E-mail: dean@commerce.uz.ac.zw
}

Received: November 13, 2013 Accepted: December 18, 2013 Online Published: January 26, 2014

doi:10.5539/ass.v10n4p145

URL: http://dx.doi.org/10.5539/ass.v10n4p145

\begin{abstract}
Job evaluation's purpose is to compare all the jobs in the organisation, one with another, with the aim of producing a rank order. This rank order may be then be subdivided into groups of jobs of the same size which can, if desired, be placed within pay ranges or grades. While this approach is clearly more appropriate to large organisations, even in small organisations judgements have to be made about how one job compares with another, otherwise no decision can be made about relative pay and status. So, in effect, even where there is no formal method of job evaluation, jobs are evaluated in any case. It is really a question of how analytical the organisation wants to be.
\end{abstract}

Keywords: rank order, subdivided, pay ranges, appropriate, relative pay, analytical

\section{Introduction}

Cushway (2003) defines job evaluation as a process for judging the relative size of importance of the job within an organisation. According to Armstrong (1992), job evaluation is a systematic method or process, as opposed to an approach that is random or non-systematic. This means that jobs are considered against the same criteria in each case which should ensure consistency.

The alternative is a non-analytical approach in which each job is considered in isolation and against what may be entirely different considerations in each case. In such a situation, it is not possible to make objective comparisons between jobs and the final judgements are likely to be inconsistent.

Job evaluation is concerned with relationships, not absolutes. It cannot measure in definitive terms the inherent value of a job to the organisation. It is essentially a comparative process: comparisons against defined standards or comparisons of the to which a common criterion or factor is present in different jobs.

Job evaluation is part of the organisation's human resource planning process. It is a systematic method or process, as opposed to an approach that is random or non-systematic. This means that jobs are considered against the same criteria in each case, which should ensure consistency.

The purpose of job evaluation is to compare all the jobs in the organisation, one with another, with the aim of producing a rank order. This rank order may be then be subdivided into groups of jobs of the same size, which can, if desired, be placed within pay ranges or grades. While this approach is clearly more appropriate to large organisations, even in small organisations judgements have to be made about how one job compares with another, otherwise no decision can be made about relative pay and status (Cushway, 2003). So in effect, even where there is no formal method of job evaluation, jobs are evaluated in any case. It is really a question of how analytical the organisation wants to be.

\section{Background to the Study}

Armstrong (1996) says that there is no choice about job evaluation, but that all organisations must make decisions on rates of pay and those decisions are based on judgements about relative job values within the organisation or on market rate imperatives or perceptions. The choice is therefore concerned not with the need to evaluate jobs but with whether or not a formal evaluation scheme is required. Many organisations seem to be quite happy to do without formal job evaluation. Their organisation structure and methods of working may, in their view, clearly indicate the relative values of roles without the need for bureaucratic and inflexible process of job evaluation. In some cases negotiations or custom and practice determine pay relativities and they see no point in superimposing job evaluation. If asked about the danger of an equal value claim they may reply that they 
are quite satisfied that their pay structure is not discriminatory and that they are certainly not going to become obsessed by equal value considerations. They may feel that a formal process would be at odds with the culture of the organisation as manifested in its flexible and non-bureaucratic approach to managing its affairs.

Other organisations believe that an orderly approach is essential in order to develop and maintain a logical and fair structure which enables them to manage relativities and minimize the risk of a successful equal value claim. The arguments in favour of a formal approach to job evaluation were set out before. In essence they are that formal evaluation schemes provide the best basis for marking fair, consistent and defensible decisions about the relative and comparable worth of jobs. Moreover a formal approach can and should be transparent.

\subsection{Objectives of Job Evaluation}

The objectives of job evaluation are to:

"provide bases for rational and equitable wage and salary structure by systematically describing and analyzing jobs and thereafter evaluating and defining levels of the job demands in basic functional terms. This is intended to provide a basis for the design and operation of a logical and equitable grade and pay structure and for managing relativities within that structure."

\subsection{Types of Job Evaluation Schemes}

The main types of Job-Evaluation Schemes are two and these are analytical and non-analytical schemes.

\subsection{Analytical Job-Evaluation Scheme}

These are schemes in which decisions about the value or size of jobs are based on an analysis of the extent to which various defined factors or elements are present in a job. These factors should be present in all the jobs to be evaluated and the different levels at which they are present indicate relative job value. The Equal Pay Regulations (1983) refer to the demands on a worker under various headings, for instance, effort, skill and decision. To meet the fundamental requirements of equal-pay for work of equal value, job evaluation schemes must be analytical.

The most common analytical approach is a point factor scheme, where there is a factor plan that defines the factors and their levels and attaches scores to each level. Following job analysis, scores for each factor are awarded and then totaled. Once the evaluation programme has been completed, the total scores for jobs indicate their rank order. This type of scheme can meet the requirements of equal law as long as it is not in itself discriminatory in either its design or its application (Stredwick, 2005).

To ensure that equity considerations are catered for in an organization, it is preferable to use only one scheme which must therefore be designed to cover the key features of each category of job at every level. The main features of analytical job evaluation are that it is systematic, judgemental, concerned with the job not the person and deals with internal relativities.

\subsection{Non-analytical Job-Evaluation Scheme}

These are schemes in which whole jobs are described and compared in order to place them in a grade or rank order, without analyzing them into their constituent partner or elements. The most common non-analytical approach is job classification in which grades in a grade structure are defined and jobs are slotted into the grades by comparing the job description with the grade definition.

Another non-analytical method is job ranking which is the process of comparing whole jobs with one another, and arranging them in order of their size or value to the organization. According to Guest (1989), the statistical technique known as paired-comparison ranking can be used and this involves comparing one job with others on the assumption that it is always easier to do this than to consider a number of jobs and attempt to build up a rank-order by multiple comparisons.

\subsection{Principles of Job Evaluation}

Job evaluation is a systematic process. This means that jobs are considered against the same criteria in each case, which should ensure consistency. The alternative is a non-analytical approach in which each job is considered in isolation and against what may be entirely different considerations in each case. In such a situation, it is not possible to make objective comparisons between jobs and the final judgements are likely to be inconsistent.

\subsection{Job Evaluation Is Judgemental}

Job evaluation is sometimes perceived and described as scientific. In any job evaluation scheme, no matter how sophisticated, where a job is placed in relation to another is a matter of judgement on the part of the evaluators. It certainly should be systematic, however, and make judgements about job using common standards. If individuals 
are left to judge job size without these guidelines, the result is that different standards and criteria are likely to be used and it will be like trying to compare eggs with apples (Westhuzen \& Abrahams, 2002).

It is important to remember that job evaluation is one of the processes to help manage the organisation and that the intention is to achieve the maximum objectivity.

\subsection{It Is About the Relative Size of Jobs}

Job evaluation is a comparative process and ultimately the aim is to compare one job with another. Allocating points to a particular job is an indication of the size of that job in relation to others in that organisation, based on the particular criteria contained in the job evaluation method used. Although some job evaluation schemes do facilitate comparisons between organisations, the key measure is one of internal relativity.

\subsection{Jobs Not People}

Central to the principles of job evaluation is that it is about jobs, not people. When jobs are being evaluated the evaluators have to forget the individuals doing them and concentrate on the content of the jobs above. This means that a high performer will not gain additional points or extra credit just for being good at his or her job. Similarly, the individual whose performance falls short of the standard required will not be penalized.

The question is often raised about the person who is undertaking more than may be strictly required in his or her job. Obviously people do change the content of the jobs and someone who is highly experienced may well take on additional responsibilities that may not originally have been part of the job. In these circumstances, if the new responsibilities have become a recognized part of the job, then they can be evaluated. However, if they are undertaken voluntarily and are not seen as an essential part of the job, they do not perform part of the job for evaluation purposes.

In similar vein, if someone is not carrying out the full range of responsibilities, the job will still be evaluated as though he or she were, although there might be an issue about performance which could have training or disciplinary implications.

\section{Research Methodology}

Methodology is defined in two major ways. In one form, the methodology is identical to a research model employed by a researcher in a particular project including basic knowledge related to the subject and research methods and the framework employed in a particular context (Lathor, 1992). In this sense, every investigation has a distinct approach and every researcher employs his/her approach which might mary from study to study. Another definition relates to the nature of approach to a theoretical and more abstract context and perceives it in conjunction with distinctive undimensional and mutually exclusive theoretical principles (Westhuizen \& Ahrahams, 2002).

Here, an approach offers the research principles which are related closely to a distinct paradigm translated clearly and accurately down to guidelines on acceptable research practices. The approach is determined not by research model but rather by principles of research entailed in a paradigm. The approaches that result from this definition are the qualitative and the quantitative approaches. As this study applies qualitative approach, below it is discussed briefly.

\section{Qualitative Approach}

The study which is under review is a qualitative or case study one. Denzin and Lincoln (1994) define qualitative research as a multi-method in focus, involving an interpretive and naturalistic approach to its subject matter. Creswell (1994) defines qualitative research as an inquiry process of understanding, based on distinct methodological traditions of inquiry that explore a social or human problem. Qualitative research is invariably conducted in the field, for this reason, it is sometimes referred to as field research (Dooley, 1992). Guba and Lincold (1992) say that qualitative research is sometimes referred to as case study research.

This means that the qualitative researchers, study things in their natural settings, attempting to make sense of or interpret phenomena in terms of the meanings people bring them. Qualitative research involves the use and collection of a variety of empirical materials-case study, personal experience, introspective, life story, interview, observational, historical, interactional and usual texts that describe routine and problematic moments and meaning in individuals' lives.

\section{Sources of Data and Sampling Method}

The study employed two sources of data collection and these are primary and secondary sources. Secondary sources included relevant academic journals, text books and publications by employment agencies. The primary 
source involved the use of well-structured questionnaires administered on 240 randomly selected respondents from Lever Brothers to ascertain if its jobs are properly graded and has payment system which is transparent and within which work of equal value receives equal pay regardless of sex. The data collected were content analyzed.

\section{Research Findings and Recommendations}

Two hundred forty (240) questionnaires were distributed to the respondents. Out of the 240 questionnaires, only one hundred sixty (160) questionnaires were returned. Of the 160 questionnaires, 60 came from senior clerks and senior managerial staff while the remaining 100 came from clerks down to the general workers.

Generally the senior clerks and the managerial staff complained that their salaries were lower than the salaries of their counter-parts in organisations around them. Clerks and general labourers complained that, since they joined the organisation, they are still sitting on the same grade notches.

However, all respondents stated that their jobs were graded. To this end, the researcher recommended to the organisation's management to see to it that the complaints were investigated and actions taken. For clerks and general workers, the researcher recommended that the promotional system be put in place.

\section{The Administration of Job Evaluation: Steps}

Like any other management programme, job evaluation administration must be systematic and well structured. It is not a "one-off" exercise which ends at the implementation stage, but it is on-going and requires continuous and consistent review of existing results, updating of records, training of those involved in its use, handling of the inexhaustible grievances or queries from employees, their representatives and line management. The steps to be undertaken are below:

\section{1) Preparation}

This stage involves the laying-down of company policy, drafting of an implementation programme, negotiation with employees' representatives, selection of the method to be used, establishment of procedures and training of all those who will be involved.

\section{2) Analysis and Evaluation of Jobs}

Job analysis should be preceded by an announcement to the entire workforce of the nature and objectives of the exercise. Thereafter, job descriptions are produced and classified.

3) Developing the Pay Structure

This stage involves the evolution of the grades which will constitute the pay structure and the pricing of the grades through salary surveys.

4) Implementation and Control

Ideally, negotiation with and involvement of workers' representatives, will have been maintained throughout the preceding stages and, at this stage, final agreement should be achieved on the new pay structure and procedures for maintaining the system. The new pay structure is then implemented and any pay anomalies or structural defects rectified.

\subsection{Policy}

Beach D (1980) says that before job evaluation is embarked upon, management should lay down its policy on the use of the technique. Such policy should specify which jobs or range of jobs will be covered by job evaluation, which system will be used, who will be responsible for which tasks and so on. Where a policy commitment has been made, it should not, without good cause and sufficient consultation with all concerned, be abrogated or varied in any way. It is imperative that such policy be stated in writing and that all concerned be made aware of its existence and implications.

\subsection{Responsibilities and Authorities}

Job evaluation affects different members of the working community differently. To employees, it may represent a means to achieve their aspirations of rising up the organizational ladder; to management it may be regarded as a device to facilitate work allocation and dispensation of rewards; to workers' representatives, it may be viewed as scale for ensuring that employees are being equitably treated on matters of pay.

Each of these parties has interests which must be protected and respected in the job evaluation process. These interests are best safeguarded by allocating certain responsibilities and authorities to the parties concerned. 


\subsection{Types of Job Evaluation Methods}

In deciding on which method to use, what must be considered is the end product rather than the means to that end. In this regard, suitability should be the principal consideration when deciding on the system of job evaluation to adopt. For example, it would be futile to use the Ranking method in a large organization employing various skills and professions, yet that same method would be very effective in a small organization employing few people (Guest, 1989).

Most methods of job evaluation in use today can be classified into two broad categories, though some methods tend to embrace both categories. They are quantitative methods, i.e. those that give a score to certain factors of the job, and non-quantitative methods which do not give any numerical scores. The methods can further be classified into traditional methods, i.e. the long-established systems, and the new methods-those which have been developed in recent years and are in most cases, derivatives from or modification of traditional methods (Stredwick, 2005).

\section{Traditional Methods of Grading Jobs}

The traditional methods of job grading are:

1) Ranking

This method involves considering all jobs in an organization and ranking them on the basis of their importance and worth. The method is very simple and easy to apply and has already been stated. It is effective for use in small, close knit organisations such as departmental stores.

Its disadvantages are that:

a) it is very subjective and thus open to challenge;

b) it is cumbersome and does not suit large organisations with a wide range of skills and professions.

2) Points rating

It involves allocating points under a number of headings or factors chosen as being characteristics of the jobs to be covered. The factors may embrace skill requirements such as judgment, decision-making, educational and experiential job requirements, effort, working conditions etc.

Its strengths are that:

a) it is easy to apply to most types of industries and jobs;

b) it is more analytical and deals with job factors;

c) it is easily explained to those affected.

Its disadvantages are that:

a) it involves many arbitrary and subjective elements in the selection of factors;

b) it is time-consuming since it involves long and costly discussions between management and worker representatives.

\section{3) Classification}

This method differs from ranking in that grade and wage levels are determined before jobs are ranked and job descriptions written defining the type of job which should fall into each group. Jobs are then allocated to groups by a committee using prepared job descriptions.

The method is relatively simple but suffers from limitations similar to those of the Ranking System. Its major disadvantage is the difficulty of evolving and writing-up grade definitions.

\section{4) Factor Comparison}

The method attempts to rank jobs and at the same time attach monetary value to the jobs. Key jobs are evaluated in terms of given factors that are thought to compose the job e.g. for manual workers:

a) mental requirements;

b) physical requirements;

c) skills requirements;

d) working conditions;

One of its advantages is that it applies detached criteria in determining the relationship which an individual job 
has to another.

\subsection{New Methods of Grading Jobs}

New methods of job grading are:

1) Paterson System

Very much applied by private sector but some public organisations also use it. This method shall be dealt with in detail later to serve as an example.

\section{2) Questionnaire Method (Q Method)}

This method has 13 grades and it involves the use of questionnaires. It uses four factors (decision-making, controls and checks, contacts with people and education and experience). Its advantage is that it is simple to use and understand and can be applied to all jobs in the organization.

\section{3) Castellion System}

This method is mostly applied by the public sector e.g. state universities, local authorities, parastatals etc. Castellion System derives its name from a combination of the Castle and Lion beer brands and was first developed by South African Breweries. It was introduced into Zimbabwe by the then Rhodesia Breweries in the early seventies and is presently used by many industrial, commercial and parastatal organisations. Castellion is a point-system which evaluates jobs on the basis of six factors, namely:

1) Decision-making: the exercise of making a choice between alternative courses of action.

2) Pressure of Work: the volume of work and the pressure under which decisions have to be made.

3) Controls and Checks: both direct and indirect controls applied to the activities of the incumbent.

4) Consequence of Error: possibility of losses which may result from wrong decisions or lack of vigilance.

5) Education: level of education required to perform the duties of the job.

6) Experience: the maximum period needed for a person with the required education to perform the duties of the job.

Factors 1 and 3-5 are allocated marks according to the complexity level of the factors, with the simplest levels being awarded the least marks. Factors 2 and 6 are coefficients which, in each case, are multiplied by the preceding factor to obtain a score. Once points have been allocated to the six factors, a total score is obtained and the job is graded by slotting it into one of the 16 grades in the system. Grade 1 is the highest and grade 16 is the lowest.

Salaman G. and Storey J. (1998) state that the system can be used in all jobs within an organization and it has the further advantage that the complexity level of jobs can be compared across different organisations and industries.

\subsection{The Peromnes System}

Originally devised in the mid-sixties, the Peromnes System of job evaluation is widely used in Southern Africa.

The system evaluates jobs on the basis of factors which are deemed to be, to some degree, characteristics of all jobs.

The eight factors are each examined and scored and the total score gives a total points value for the job, which is then graded. The Peromnes System has 19 grades-1 being the highest and 19 the lowest-which are standardized nationally so as to achieve direct comparability of jobs in different organisations.

\subsection{The Hay Guide Chart Profile Method}

This is an analytic system based on analyzing each job in terms of three criterial-know-how problem-solving and accountability.

Armstrong M. (1996) says that the method flows from the concept that all jobs are required to make a contribution to the achievement of results-this is the accountability of the job. In order to meet this accountability, the job holder must bring to bear certain kinds and degrees of knowledge, skills and experience-know-how. In addition, these inputs are used in analyzing, evaluating, reasoning, arriving at and making conclusions-problem-solving.

These three elements, broken down into components, are common to all jobs and between them they cover all the factors which bear on the size of the job. These elements are derived from extensive experience of the attributes of job holders. 
A numerical scale (expressed in tables known as "Guide Charts") is used to record the judgment made on each of the common elements and the sum of these figures is the evaluation of the job.

This gives an indication of the size of a job relative to other jobs. The distribution of this total among Know-How, Problem-solving and Accountability gives an indication of the shape of the job or Job Profile.

\subsection{Paterson System}

\subsubsection{The Advantages of the Paterson System}

After careful study of the various job evaluation systems, a company could select the Paterson System for the following reasons:

The Paterson system is simple, both as regards implementation and general understanding. This ensures that both workforce and management can understand it and participate meaningfully in its implementation.

The Paterson System is flexible in that it can be applied to all the jobs in the company from the bottom to the top.

At the end of the Job Evaluation exercise, a visual pay structure of the company can be produced on logarithmic graph paper.

The Paterson system is sometimes referred to as the "Decision Band" method of job evaluation. Professor Paterson (1997) says that "decision-making" affects everyone in any organization. The different types of decisions are made at each level in the organization. Professor Paterson concluded from his extensive research that there are only six "decision bands" in any organization, irrespective of its socio-cultural setting. The six decision bands outlined below accommodate the whole range of jobs from the bottom to the top of any organizational structure.

\subsubsection{Decision Bands}

\section{Decision Band}

Band F

\section{Nature of Decisions}

Policy Making Decisions

Made by top management such as the Board of Directors of a company. The goals of the organization are set.

Band E

\section{Programming Decisions}

Made by senior management such as General Managers or Heads of Major Division. These are major strategies for implementing the policies made at $\mathrm{B}$ and $\mathrm{F}$.

\section{Band D \\ Interpretive Decisions}

Made by middle management. They interpret the Action Plans and Programmes set at B and E and make tactical decisions on how to achieve these programmes.

\section{Band C \\ Routine or Process Decisions}

Personnel in Band C decide how to carry out the plans interpreted at B and D. They decide on the best processes required to carry out the work.

\section{Band B \\ Automatic or Operative Decisions}

These are decisions relating to the operations within the process set at Band $\mathrm{C}$. The worker decides how to carry out instructions concerning what to do and where to do it.

\section{Band A Defined or Elemental Decisions}

At this level in an organization, discretion is very limited. The worker controls only the elements which make up an operation, e.g. speed of working.

\section{Conclusion}

Job evaluation is part of the organisation's human resource planning process. Once the overall strategy and objectives have been determined and the structure has been developed, the next step is to establish the required level of human resources, i.e. to get the right people with the right skills in the right place at the right time. This in turn means having effective selection process and all the necessary system to ensure the retention and motivation of staff. Part of this process will inevitably involve deciding on the relative size of jobs if no other reason than to ensure that pay is at a level that will attract people and more importantly, that those within the organisation will feel that bigger jobs receive bigger rewards. 


\section{References}

Armstrong, M. (1992). Personnel Management Practice. Kogan Page.

Beach, D. S. (1980). Personnel: The Management of People at Work. MacMillan Publishing Company.

Cushway, B. (2003). Human Resource Management. Crest Publishing House. New Delhi.

DeCenzo, D., \& Robbins, P. (1996). Human Resources Management. Jonhs Wiley \& Sons Inc.

Drucker, P. (1955). The Practice of Management. Heunemann: London.

Guest, D. (1989). Personnel and Human Resources Management. Can you tell the difference. January 1989.

Likert, R. (1966). In Harper, \& Row (Eds.), New Patterns of Management. New York.

Salaman, G., \& Storey, J. (1998). Human Resource Management: Strategic Introduction. Blackwell Publishers Ltd.

Stredwick, J. (2005). An Introduction to Human Resource Management. Legoprint: S.P.A.

Westhuzen, G., \& Abrahams, M. (2002). Research Paradigms in Cognitive Education. Wadsworth Publishing Company.

\section{Copyrights}

Copyright for this article is retained by the author(s), with first publication rights granted to the journal.

This is an open-access article distributed under the terms and conditions of the Creative Commons Attribution license (http://creativecommons.org/licenses/by/3.0/). 